\section{An Update on Choroidal Layer Segmentation Methods in Optical Coherence Tomography Images: a Review}

\author{
Reza Alizadeh Eghtedar ${ }^{1 \oplus}$, Mahdad Esmaeili², Alireza Pey- \\ man³, Mohammadreza Akhlaghi3 ${ }^{3}$ Seyed Hossein Rasta ${ }^{2,4,5 * \odot}$
}

\begin{abstract}
Choroid is one of the structural layers, playing a significant role in physiology of the eye and lying between the sclera and the retina. The segmentation of this layer could guide ophthalmologists in diagnosing most of the eye pathologies such as choroidal tumors and polypoidal choroidal vasculopathy. High signal-to-noise ratio and high speed imaging in Spectral-Domain Optical Coherence Tomography (SD-OCT) make choroidal imaging feasible. Several variables such as pre-operative axial length (AXL), time of day and age affect thickness of the choroidal vascularization and should be considered for segmentation of this layer. These days most of the eye specialists manually segment the choroidal layer which is time-consuming, tiresome and dependent on human errors. To overcome these difficulties, some studies have introduced different automatic choroidal segmentation methods. In this paper, we have conducted a comprehensive review on existing recently published methods for automatic choroidal segmentation algorithms.
\end{abstract}

Citation: Alizadeh Eghtedar R, Esmaeili M, Peyman A, Akhlaghi M, Rasta SH. An Update on Choroidal Layer Segmentation Methods in Optical Coherence Tomography Images: a Review. J Biomed Phys Eng. 2022;12(1):1-20. doi: 10.31661/jbpe.v0i0.1234.

Keywords

Choroid; Optical Coherence Tomography (OCT); Retina; Ophthalmology

\section{Introduction}

工 $\mathrm{n}$ the last few years, computer-based algorithms developed for automatic analysis of retinal images to detect various retinal lesions, segment retinal vessels and, particularly, for Optical Coherence Tomography (OCT) volume analysis for detection of intraretinal cysts or subretinal fluid and choroidal layer segmentation [1-5]. The choroid, playing a significant role in the physiology of the eye, is a layer between the sclera and the retina. The change in choroidal thickness depends on age and the increased levels of myopia in adults [6]. Moreover, different pathologies of the eye such as diabetic retinopathy can cause some alterations in the thickness of the choroid [6]. One of the common choroidal imaging techniques is indocyanine green angiography (ICGA), (Figure 1), utilizing near-infrared (NIR) for both excitation and detection in order to yield much greater penetration rate than fluorescein angiography. But this technique contains some disadvantages, including low depth contrast and the need for the dye injection which is an invasive procedure and may have some side effects [7]. To solve these issues, a new imaging technique, named OCT, (Figure 2), was introduced by Huang
${ }^{1} \mathrm{MSc}$, Department of Medical Bioengineer-

ing, School of Advanced Medical Sciences, Tabriz University of Medical Sciences, Tabriz, Iran

${ }^{2} \mathrm{PhD}$, Department of Medical Bioengineering, School of Advanced Medical Sciences, Tabriz University of Medical Sci-

ences, Tabriz, Iran

${ }^{3} \mathrm{MD}$, Department of Ophthalmology, Isfahan University of Medical Sci-

ences, Isfahan, Iran

${ }^{4} \mathrm{PhD}$, Department of Medical Physics, School of Medicine, Tabriz University of Medical Sciences, Tabriz, Iran

${ }^{5} \mathrm{PhD}$, Department of Biomedical Physics, School of Medical Sciences, University of Aberdeen, Aberdeen, UK

*Corresponding author: Seyed Hossein Rasta

Department of Medical Bioengineering, School of Advanced Medical Sciences, Tabriz University of Medical Sciences, Tabriz, Iran

E-mail: s.h.rasta@abdn. ac.uk

Received: 28 August 2019 Accepted: 30 October 2019 


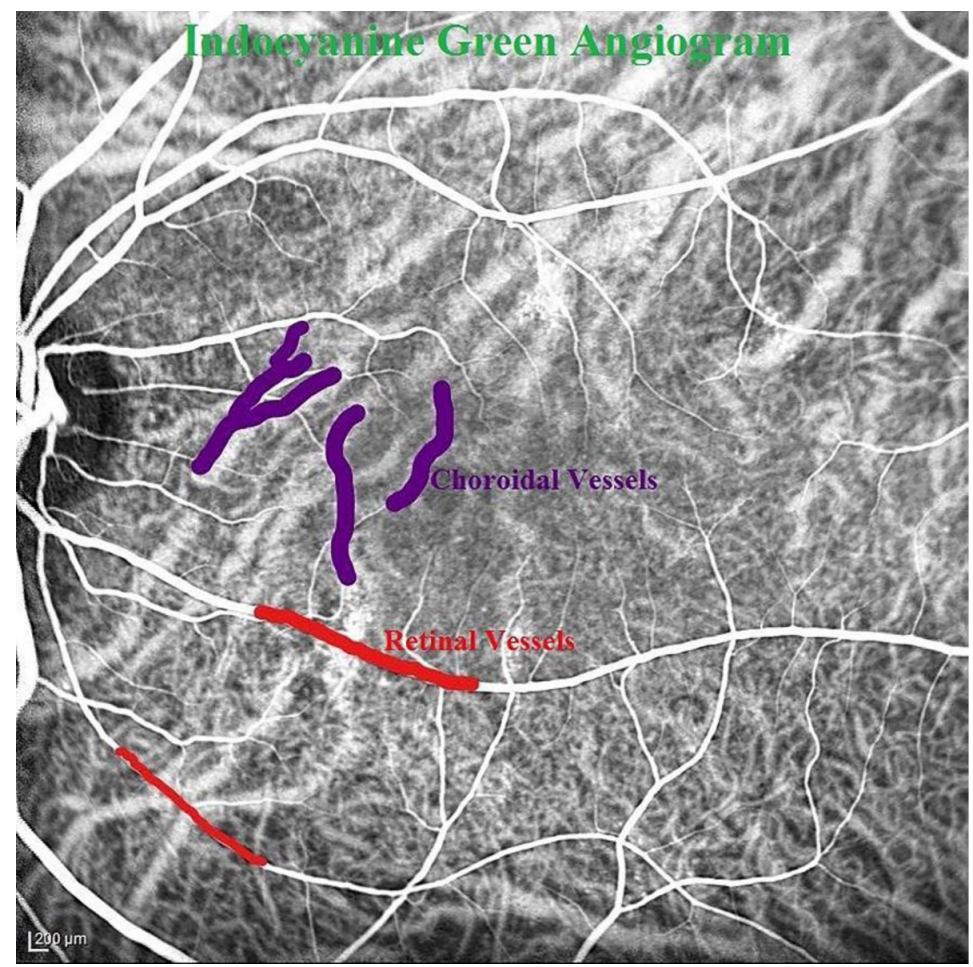

Figure 1: A layer of the posterior part of the eye, imaged by Indocyanine Green Chorioangiography (ICG). The choroid layer is deeper than the retina and contains a unique network of blood vessels ( 8 bit image).

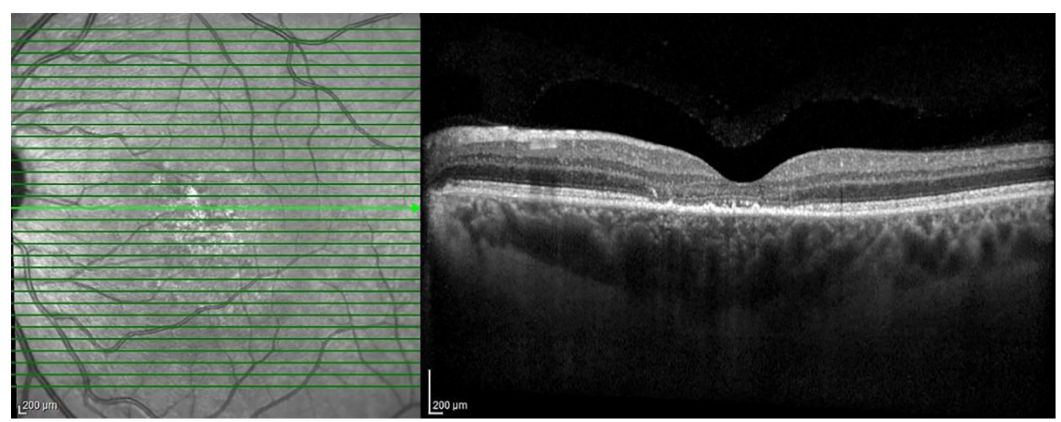

Figure 2: Optical Coherence Tomography (OCT) is a technique, used in ophthalmology and optometry for imaging of the retina (8 bit image).

and Colleagues in 1991 [8] that is a noninvasive and noncontact technique by which the images of human retina become provided [9]. Time-domain OCTs (TD-OCT), which are using a moving reference mirror in order to measure the reflection time of the light first became publically available in 2002-2003. The mechanical movement of the reference mirror causes reduction in image quality and increases the total processing time [10]. To overcome the mentioned defects of TD-OCTs, Spectral domain OCT (SD-OCT) was introduced in 2006. An SD-OCT uses low-coherence interferometer with a high-speed spectrometer detecting the echoes of light simultaneously by measuring the interference spectrum, instead of moving parts in TD-OCTs. Therefore, in SD-OCTs, the image quality, density of volume scans and the resolution of the images increase in comparison with TD-OCTs. 
Because of the relatively high signal-to-noise ratio of Spectral-Domain Optical Coherence Tomography (SD-OCT) compared with timedomain OCT, better visualization of fine detail in deeper layers of the choroid and any part of the retina was seen [10]. In addition, the Enhanced Depth Imaging (EDI) OCT has been used in recent works of choroidal segmentation, places a zero delay line on the choroid to obtain high-resolution cross-sectional images of the choroid [11]. Nowadays, most of the ophthalmologists have to manually define the boundaries of the choroid for measuring of its thickness and there is not available software for the segmentation of choroid, on current OCT systems [12].

Like many other things, automatic segmentation of choroidal boundaries has its own difficulties due to low contrast ratio [13]. The objective of this paper is to review the different techniques for automatic segmentation of choroidal thickness and to introduce the best existing technique according to the gained results of articles.

This paper is organized as follows: 1) We gave a brief introduction of this study. 2) We describe the choroidal characterization in various retinal diseases. 3) The available techniques for automatic segmentation of choroidal region are introduced. 4) Available metrics for choroidal thickness measurement have reviewed. 5) The paper is discussed. 6) The paper is concluded.

\section{Choroidal characterization in var- ious retinal diseases \\ 1- Choroidal thickness in normal eyes}

The choroidal thickness was measured manually from the outer boundary of the Retinal Pigment Epithelium (RPE) to the inner border of the sclera [14] and contained regional changes in the posterior pole and changed according to the location of the macula. The choroidal layer is the thickest at the subfoveal location, the thinnest nasally, and the thinner temporally $[15,16]$.

Age is another effective variable that should be considered when comparing the thicknesses of the choroid $[16,17]$. In normal eyes, the range of subfoveal choroidal thickness is on average 287-332 $\mu \mathrm{m}$ [15-17]. Although the changes in choroidal thickness in normal eyes may not occur at the same speed, thinning of the choroid happens with a rate of 1.56 $\mu \mathrm{m}$ per year in the area of subfoveal location [16]. In addition to the age, daily fluctuations in choroidal thickness can be related to systolic blood pressure, refractive error, and axial length [18].

2- Choroidal thickness in Age-related Macular Degeneration (AMD)

The origin and development of the disease procedure in AMD is totally unclear. With senescence, lipoid deposition in the choroid, Bruch's membrane, and sclera increased [19]. The reduction of choroidal perfusion and increase of resistance to choroidal blood flow can be some of the results of this deposition, which may lead to the AMD progression [20]. There are conflicting reports about the choroidal thickness in early AMD patients [21, 22]. In a study, choroidal thickness has been found similarly between the both groups of 16 eyes in an age-matched control and 16 eyes with early AMD [22]. In the other study, it has been shown that the average choroidal thickness of 17 Korean eyes with early AMD was obviously less than the age-matched control eyes [21]. In Manjunath et al. showed that the choroidal thickness of eyes with AMD, on average, was thinner than normal controls. In addition, the eyes with nonexudative AMD were thicker than eyes with exudative AMD [23].

3- Choroidal thickness in Diabetic Retinopathy (DR)

Although diabetes mellitus (DM) affects the choroid [24], there is not enough clinical information about diabetic choroidopathy. It seems that patients, suffering from diabetic retinopathy, have a thinner choroid [25-29]. In a study, the thickness of choroid in normal 
control eyes did not have any difference with eyes suffering from nonproliferative diabetic retinopathy. Amazingly, treated eyes suffering from proliferative diabetic retinopathy or diabetic macular edema had thinner choroids than their normal peers [28] because choroidal blood flow $(\mathrm{CBF})$ decreased in diabetic patients [30]. Querques et al. [27] proposed that the decrease in thickness of choroid is related to a decreased CBF. It has shown that; as compared with normal controls, the inferior and central choroid were thinner in diabetic eyes. In this study, the degree of diabetic retinopathy also indirectly correlated with thickness of the choroid, but the thickness of the choroid in diabetic eyes without retinopathy was as similar as the controls $[25,26]$. Still, what causes the thinning of the choroid is not clear because thinning of the choroid increases the amount of choriocapillaris atrophy [26]. Enhanced Depth Imaging Optical Coherence Tomography (EDI-OCT) imaging of choroid could be a functional technique to study the participation of the circulation of the choroid to the general visual impairment [14].

\section{4- Choroidal thickness in glaucoma}

The imaging of the human optic nerve head by EDI-OCT, could be helpful in investigation of the origin and development of glaucoma $[31,32]$. Studies on a group of healthy people show that the central lamina cribrosal thickness has a relationship with age without any relationship with thickness of central cornea or axial length [33]. Besides, comparing the lamina cribrosa with normal controls or glaucoma suspects shows that the lamina cribrosa is thinner in glaucomatous eyes [31, 34].

5- Thickness of the choroid in patients with Central Serous Chorioretinopathy (CSC)

It seems that CSC comes from extremely high permeability of choroidal vascular [35]. Multiple studies have shown that the thickness of the choroid increases in CSC [36-40]. In a study, to measure the volume between the segmented lines, at first choroidal macu- lar, maps had been constructed by manually segmenting the thickness of the choroid and then the automated software had been used [37]. Furthermore, it was shown that the increased thickness of the choroid seen in CSC was not limited to focal points and was a diffuse phenomenon throughout the macular area [37]. The most of time, the thickness of the choroid increases in both the fellow and the affected eye $[36,41]$. These findings are consistent with the findings of the indocyanine green angiography (ICGA), suggesting bilateral vascular hyperpermeability of the choroid even in the eyes without subretinal fluid [42]. Thickness of choroid decreased, after treatment of active CSC with either half-or full-fluence photodynamic therapy $[37,39,40]$. Based on the choroidal thickness in EDI-OCT images, it can be concluded that sildenafil citrate may be a risk factor for CSC because it increases the thickness of the choroid $[43,44]$.

6- Choroidal thickness in Diabetic Macular Edema (DME)

In a study carried out by Tamer et al. the subfoveal choroidal thickness (SFCT) was evaluated in DME. OCT images of 106 eyes, were used in nonrandomized case control study, which 37 and 69 of the cases were healthy and suffering from DME, respectively. In the DME group, the SubFoveal Choroidal Thickness (SFCT) was considerably thinner $(193.4 \mu \mathrm{m})$ than the control group $(282.6 \mu \mathrm{m})(P=0.001)$. Furthermore, the SFCT was considerably related to central foveal thickness (CFT) and vision, in the DME group $(P<0.05)$. It can be concluded that the DME is related to a notable decrease in SFCT [45].

7- Choroidal thickness in Multiple Sclerosis (MS)

Ebru Esen et al. showed that EDI-OCT images of patients with multiple sclerosis (MS) were used to evaluate the thickness of the choroid. The sixty eyes of 30 healthy subjects and 68 eyes of $34 \mathrm{MS}$ patients were evaluated in this observational comparative study. The mean SFCT in MS patients was considerably 
reduced $(310.71 \pm 61.85 \mu \mathrm{m})$ in comparison with healthy controls $(364.85 \pm 41.81 \mu \mathrm{m})(\mathrm{p}$ $<0.001)$. In MS patients, the reduced thickness of choroid was related to longer duration of disease $(r=-0.28, p=0.019)$ [46].

\section{Automatic segmentation methods of choroidal thickness from OCT im- ages}

There are several considerable advantages of automatic segmentation of choroidal thickness over manual segmentation. From viewpoint of experts, automatic segmentation is time-saving and has high reproducibility and zero intra- and inter-observer variability [47]. Observing the OCT images, it is clear that the manual segmentation of the choroid has intricate process, especially for Outer Choroidal Boundary (OCB) detection because of its weak border features and low contrast; an example of automatic and manual segmentation results has been shown in Figure 3 [6].

Vedran Kajić et al. presented a two-step statistical model based on shape and texture for automatic choroidal segmentation of pathologic and normal eyes. A new dynamic programming method was used to detect the location of the choriocapillaris boundary, RPE and Bruch's membrane. The choroidal-scleral interface (CSI) was segmented by the use of statistical model. In the other words, they segmented the CSI and RBC boundary by the use of neural network, convex hull, active appearance model and Dijkstra's shortest path. In order to find the shortest path between nodes in a graph, the algorithm of Dijkstra's shortest path is used that was introduced by Edsger W. Dijkstra in 1956. This algorithm has different types; the original type of Dijkstra finds the shortest path between two nodes, producing a shortest path tree, fixes a single node as the source node in the graph and finds shortest paths from all other nodes to the source [49]. This algorithm was strong even in presence of speckle noise and other artifacts. 871 B-scans of 12 eyes, which were segmented manually, were evaluated and the results showed an average error rate of $13 \%$. It was first-ever that an automatic method for segmentation of the choroid successfully implemented in the wide data set. The advantage of this method was its accurate boundary detection even in the existence of eye diseases on a wide dataset. However, it needs 30 s for processing of each image and also requires large training set to include all possible variations [50].

In a study by Teresa Torzicky et al. a new tissue specific polarization contrasts mechanisms based on method presented to automatic segmentation of the choroidal thickness in the
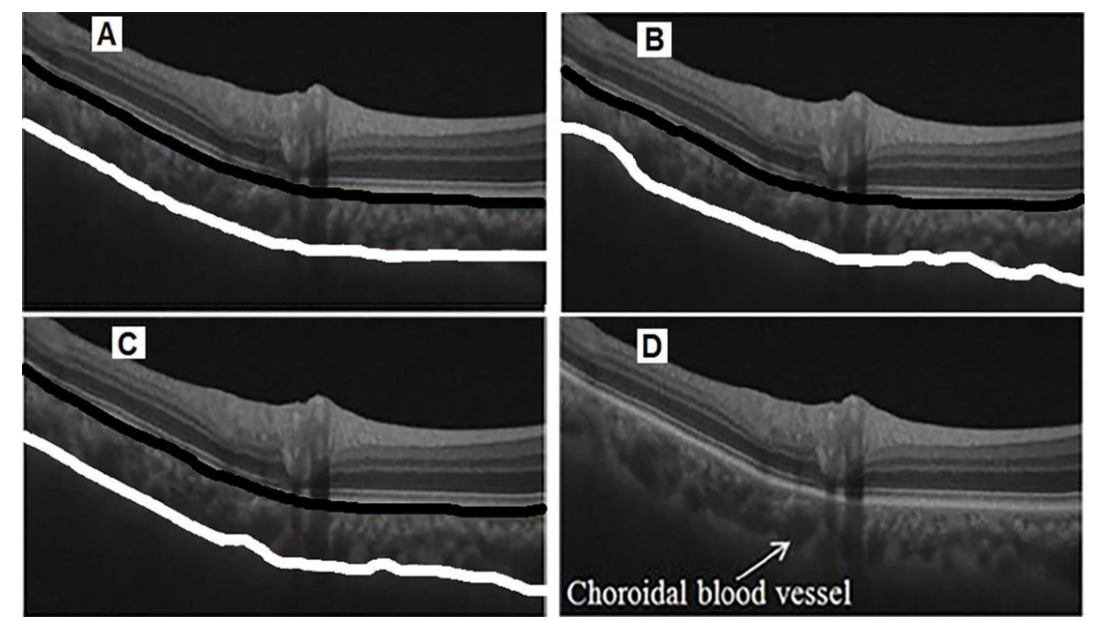

Figure 3: (A) Specialist 1. (B) Specialist 2. (C) Graph theory method. (D) Original image (8 bit image), [Adapted] with permission from [Chen Q et al., 2015] (C) The Optical Society [48]. 
human eye, using a swept source polarization sensitive optical coherence tomography (PS-OCT), operating at a center wavelength of $1040 \mathrm{~nm}$. The technique of thresholding based on the degree of polarization uniformity (DOPU) and the position of the retardation was used, so that the RPE, (the anterior boundary of the choroid) was first segmented based on depolarization, then the CSI was found based on the double refraction of the sclera. The experimental results on five healthy eyes showed that the mean standard deviation of thickness measurement was $18.3 \mu \mathrm{m}$. This method was fast and simple with a good repeatability but the proposed method was evaluated on a small PS-OCT images and the accuracy of the boundary segmentation was not analyzed [51].

Jing Tian et al. introduced an accurate and fast algorithm in order to automatically measure the thickness of the choroid. The upper boundary of the choroid was detected using graph-based dynamic programming and the lower boundary was detected by looking for the biggest value of the gradient above RPE. The time of processing for each image was about $2 \mathrm{~s}$ and the mean Dice's coefficient on 10 EDI-OCT images was $94.3 \%$, which showed great compatibility with manual labeling. Although this method has good dice coefficient index, it does not perform properly in low quality images or pathological states [52].

Li Zhang et al. proposed a 3D method for quantification of choriocapillaris-equivalent thickness of the macula and choroidal vasculature thickness and choroidal vessels segmentation, on 3D SD-OCT images of a 24 normal subjects while each subject was imaged twice. The choroidal layer was automatically segmented using graph based multilayer segmentation approach [53]. The average choriocapillaris equivalent thickness was $23.1 \mu \mathrm{m}$ and average thickness of the choroidal vasculature in normal subjects was $172.1 \mu \mathrm{m}$. Moreover, the Dice coefficient was $0.78 \pm 0.08$. It can be concluded that this proposed method has illustrated good reproducibility and also help to diagnosis the eye diseases affecting choroid, but it contains three limitations as follows: the study of reproducibility in normal subjects, the use of relatively small number of subjects and the achievement of successful segmentation results for two repeat scans in just over 24/43 subjects [54].

Zhihong $\mathrm{Hu}$ et al. introduced an automatic choroidal layer segmentation algorithm in SD-OCT volume scans using graph-based multistage approach. Thirty randomly chosen macular SD-OCT volumes $(1024 \times 37 \times 496$ voxels, Heidelberg Spectralis) were obtained from 10 subjects with non-neovascular AMD and 20 healthy subjects. Experimental results showed that the absolute and mean differences between the manual segmentation and automated algorithm for the choroid-sclera junction (CSJ) were $21.39 \pm 10.71 \mu \mathrm{m}$ and -3.90 $\pm 15.93 \mu \mathrm{m}$ and for the outer RPE boundary, were $3.15 \pm 3.07 \mu \mathrm{m}$ and $-0.74 \pm 3.27 \mu \mathrm{m}$. There was an excellent agreement between the manual and automatic algorithm of choroidal segmentation in both of the eyes with nonneovascular AMD and normal eyes but one of the disadvantages of this study was that only use of anisotropic SD-OCT volumes [55].

In a study carried out by Sieun Lee et al. EDIOCT images of 44 patients with nonneovascular AMD were used and the reproducibility and mutual agreement of automated algorithm in EDI-OCT images of eyes with nonneovascular AMD were compared with the subfoveal choroidal thickness measurements by expert raters. Subfoveal thickness of the choroid was segmented manually by two specialists and automatically by the proposed graph-based method. The automated and manual measurements of the choroidal thickness were compared with drusen area, mutual agreement and reproducibility. The mean subfoveal thickness of the choroid was $209 \pm 53 \mu \mathrm{m}$ for the automated algorithm, $246 \pm 63 \mu \mathrm{m}$ for the first rater and $214 \pm 68 \mu \mathrm{m}$ for the second rater. This algorithm generally gained smaller choroidal thickness than the raters and its repeatability 
was analogous to the manual measurements. It concluded that automatic measurement of subfoveal choroidal thickness can be used in clinical trials and practices, with the possibility of reducing labor cost [56].

Huiqi Lu et al. is presented a new automated choroidal segmentation method which automatically segments the Inner Choroidal Boundary (ICB) using a two-step fast active contour model and then allows a real-time human-supervised automated segmentation on the Outer Choroidal Boundary (OCB). To evaluate the agreement between automated and manual measurements, Dice's coefficient (DSC) was evaluated on 30 images of diabetic patients. The mean DSC value was $92.7 \%$ (standard deviation 3.6\%) in the range of $85.5 \%$ to $98.1 \%$. The experimental results demonstrated that this method can achieve high segmentation accuracy and also one of the advantages of this method is that this method can also segment the choroidal layer in the EDI OCT images of other OCT devices [12].

In a study by David Alonso-Caneiro et al. for segmentation of the ICB and OCB, a graphsearch based method was presented. The OCT images were denoised, and enhanced in preprocessing step. The OCB detection algorithm was based on graph-cut, Dijkstra's shortest path and a dual brightness probability gradient while the ICB was detected based on a simple edge filter and a directional weight. The data sets consist of 1083 B-scans of pediatric and 90 B-scans of adult population. The mean absolute error (MAE) was $12.96 \mu \mathrm{m}$ (SD 9.00 $\mu \mathrm{m})$ for pediatric and $16.27 \mu \mathrm{m}$ (SD 11.48 $\mu \mathrm{m})$ for adult, also the mean dice coefficient (mean DC) was 97.3\% (SD 1.5\%) for pediatric and $96.7 \%$ (SD 2.1\%) for adult. As shown in Figure 4, the experimental results showed that, this method provided powerful detection of the choroidal boundaries. The advantages of this method are high repeatability, high accuracy and its evaluation on a large dataset from adult and pediatric populations, but their proposed method has been tested only on high quality dataset [6].

In a study by Danesh et al. they used a texture-based algorithm in order to segment the choroid and dynamic programming to determine the location of the RPE. Furthermore, they segmented the Bruch's membrane (BM) by searching the pixels with the biggest gradient value below the RPE. Moreover, the wavelet based features to create a Gaussian mixture model (GMM) were used to segment the CSI. This algorithm was tested on 100 EDI OCT images and also compared with manual segmentations. The experimental results exhibited an unsigned error of $9.79 \pm 3.29$ pixels for choroid detection and $2.48 \pm 0.32$ pixels for $\mathrm{BM}$ extraction. This study represents that this method is accurate and efficient on the good quality images but it does not perform properly on the images with low quality and eye

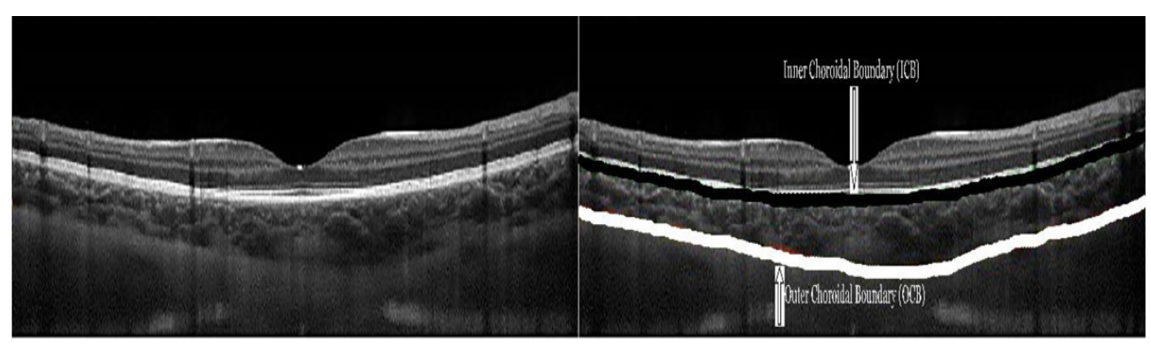

Figure 4: Right column shows the automatically segmented choroidal boundaries and left column shows the original B-Scan images. White refers to the automatic segmentation of the Outer Choroidal Boundary (OCB), and black refers to the automatic segmentation of the Inner Choroidal Boundary (ICB) (8 bit image), [Adapted] with permission from [Alonso-Caneiro D et al., 2013] (C) The Optical Society [6]. 
disease [8].

In a study by Bianca S. Gerendas et al. the data set consists of the SD OCT scans from 284 eyes of 142 patients with Diabetic Macular Edema (DME) and from 20 controls. The thickness of the choroid was analyzed using the graph-based method called the Iowa. The experimental results showed that total choroidal thickness was reduced in DME $(175 \pm 23$ $\mu \mathrm{m})$. They are concluded that the automated segmentation method is a reliable way in order to evaluate the thickness of choroid in eyes with DME and in comparison to other state of the art studies, the advantage of this method is that usually only 1 single subfoveal measurement is used, but this study is evaluated over 65000 available scanning points from the entire available B-scans set [57].

N. Srinath et al. used structural similarity (SSIM), adaptive Hessian analysis and level set technique in order to automatic segmentation of choroid. Experimental results were presented using SDOCT images and showed that the proposed method hugs choroid vessels while the manual segmentations were smooth curve below them [58].

In a study by Kiran Kumar Vupparaboina et al. tensor voting, structural similarity index, and eigenvalue analysis of the Hessian matrix were used to automatically segment choroi- dal thickness from SD-OCT images. Manual and automated segmentation results on $485 \mathrm{~B}$ scans, matched visually. Moreover, the correlation between automated and manual method was greater than 99.6\%. As shown in Figure 5 , the results of automated choroidal volume estimation were in close agreement with that of manual methods. The proposed method was evaluated on a large dataset from the adult population with high correlation with manual segmentation and high repeatability, but it takes more evaluation time where tensor voting accounts for about $70 \%$ of the computation [59].

Qiang Chen et al. proposed an automated method for choroid segmentation from HDOCT images, including the segmentation of BM and CSI. They used thresholding, gradual intensity distance, graph min-cut-max-flow and the energy minimization technique. The mean overlap ratio and choroid thickness difference between this method and manual segmentations was $85.04 \%$ and $6.72 \mu \mathrm{m}$. Quantitative and qualitative results with 212 HD-OCT images showed high segmentation accuracy for both of the normal and abnormal cases [48]. Besides, Tian et al. showed that this method was preferable to the proposed method [13]. The disadvantage of this method is that the detection of BM based on threshold-

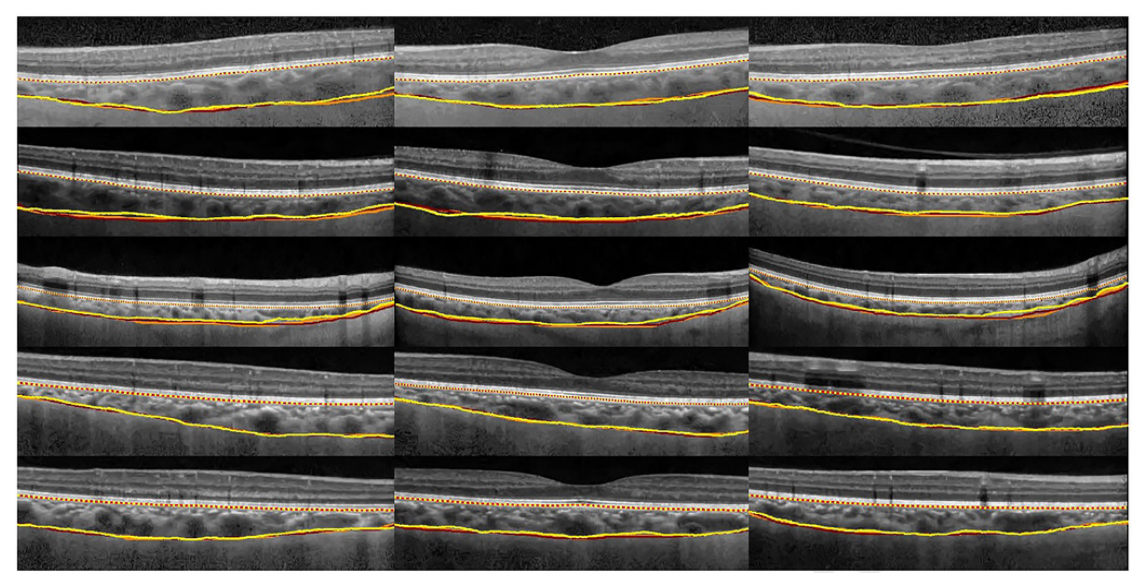

Figure 5: Yellow refers to automated segmentation; orange and maroon refer to two manual segmentations (8 bit image). Reprinted from; Vupparaboina KK et al, Comput Med Imag Graph. 2015;46:315-27. Copyright (2021), with permission from Elsevier [59]. 
ing will not work for all OCT images containing pathology.

Fei Shi et al. proposed an automated 3D method for choroidal segmentation, including the segmentation of the CSI and the Bruch's membrane $(\mathrm{BM})$. Two ancillary borders are found using modified canny operators. The primary CSI and the BM were segmented using 3D gradient-based graph search method. The CSI boundary was refined by adding a regional cost, calculated from the wavelet-based gradual intensity distance. To evaluate the automatic segmentation accuracy, reproducibility test was performed and results on 32 normal eyes were compared with manual segmentations. The mean difference of choroidal thickness from the manual segmentation was 19.16 - $4.32 \mu \mathrm{m}$. In addition, the volume quantification reproducibility was high statistically and the segmentation error was remarkably smaller than the interobserver variability. As shown in Figure 6, both qualitative and quantitative analyses demonstrated that this segmentation method had a good performance [60].

In a study by Michael D. Twa et al. OCT scans were obtained from 30 healthy eyes and the repeatability, accuracy and speed, of the proposed method were compared with manual one. The automated segmentation method was based on graph theory, dynamic programming, and wavelet-based texture analysis. The choroidal thickness measurements had similar repeatability between segmentation methods (automated (limits of agreement) LoA: \pm 14 $\mu \mathrm{m}$; manual LoA: $\pm 15 \mu \mathrm{m})$. At the foveal center, the mean choroid thicknesses were $259 \pm$ $23 \mu \mathrm{m}$ (automated) and $263 \pm 24 \mu \mathrm{m}$ (manual). Automated segmentation was 200 times faster than manual segmentation (4 vs 780 seconds). It can be concluded that automated segmentation by the use of graph theory and dynamic programming is a reliable, fast and accurate method. The proposed method was nearly 200 times faster than manual segmentation methods [61].

In another study by Xiaodan Sui et al. a convolutional network based architecture presented in which raw pixels were used to instruct an optimal graph-edge weight. This multi scale method merges global and local information from the OCT image. The experimental results on 912 B-scans indicated that this method has a better performance than manual methods, behaves accurately without any difference between OCT images of healthy people and patients, also is helpful for large scale quantitative choroidal studies and improves the diagnosis of patients with eye diseases affecting the choroid [9].

In a study by Qiang Chen et al. a three-dimensional (3D) graph search method was used and results with 768 images, including 2 DR and 2 AMD patients, 2 healthy persons, and 210 B-scan images from other 21 patients and 8 healthy persons showed that this method has high accuracy. The overlap ratio and mean choroid volume difference between the automatic and manual segmentations for 6 cubes

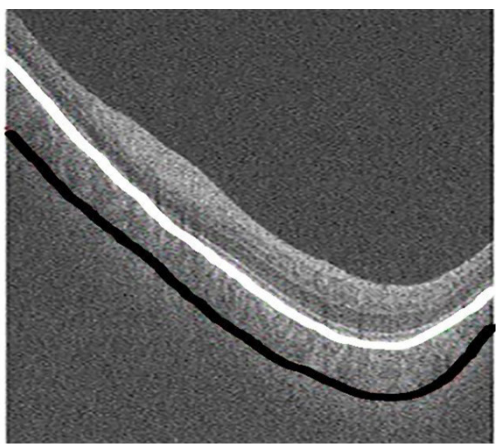

Figure 6: Black and white curves refer to Choroidal-Scleral Interface (CSI) and Bruch's membrane (BM), relatively (8 bit image), [Adapted] with permission from [Shi F et al., 2016] [60]. 
were $88.56 \%$ and $1.96 \mu \mathrm{m}^{3}$, respectively. As a conclusion, this method contains high stability and accuracy on the 3D choroid segmentation of SD-OCT images [62].

In a study by Javier Mazzaferri et al. a new automatic algorithm based on graph theory was developed in order to detect the choroidal boundaries on OCT images. This software automatically builds a 2D thickness map and segments the posterior and anterior interfaces of the choroid. At least, the proposed method was performed on database of 280 patients as well as specialists. Finally the performance of this method was similar to manual segmentation (all medians were smaller than $11 \mu \mathrm{m}$ ) for the CSI, whereas the commercial software produces larger deviations (more than $30 \mu \mathrm{m}$ ) due to smoothing [63].

Al-Bander et al. presented an accurate and fast method for choroidal segmentation based on a deep learning algorithm without user intervention. They used the dataset of 169 EDIOCT images to evaluate their proposed method. First, in order to extract the super pixels (patches), the simple linear iterative clustering (SLIC) algorithm was applied. Then, the extracted patches were enhanced by increasing contrast of the region of interest. Finally, in order to label regions into non-choroid or choroid, they fed the patches to convolutional neural network. This proposed method got DC of $89.76 \%$ and accuracy of $98.01 \%$, showing the effectiveness of this method [64].

Chen et al. proposed a learning based method for choroidal segmentation using convolutional neural networks. They used 62 EDIOCT images of AMD patients, which have been manually segmented. Twelve of $62 \mathrm{im}$ ages were used for testing and 50 of 62 images were randomly selected and used for training. The mean Dice coefficient obtained from comparison of automated and manual segmentation was $0.82 \pm 0.10$. It could be concluded that this proposed method demonstrates good accuracy in choroidal segmentation on EDIOCT images of patients with AMD [65].
Wang et al. presented an automatic technique for choroidal layer segmentation in 3D OCT images. They used 3D nonlinear anisotropic diffusion filter for image enhancement and removing the speckle noise, then the level set and Markov random field methods were used to approximate the boundary of choroid. Thirty 3D OCT scans of thirty healthy subjects with ages between 20 to 85 years were used at this study. Experimental results showed that the mean signed difference was $1.59 \pm 1.65$ pixels and the mean unsigned difference was $2.17 \pm 1.77$ pixels, also the mean Dice's coefficient was $90 \pm 4 \%$. The comparison between the automatic and manual segmentations indicates that this technique can accurately and successfully segment the posterior boundary of choroid [66].

Hussain et al. presented a method for segmentation of choroid from EDI-OCT images. For CSI segmentation, the Dijkstra's shortest path algorithm was used. The outer boundary of CSI was determined approximately and combined with the CSI edge segmentation in order to choose the best edge weight. This method was applied on 190 B-scans of 10 subjects. The proposed method was compared to the results from the manual segmentation and available results by Chen et al. [48] and Tian et al, [13]. For finding the CSI boundary, the mean root-mean-square error (RMSE) was $7.71 \pm 6.29$ pixels, which was sizably lower than the RMSE for the two other modern methods $(36.17 \pm 11.97$ pixels and 44.19 \pm 19.51 pixels). The correlation coefficient of this method was 0.76 , while it was 0.51 and 0.66 for the other two methods. Moreover, the interclass correlation coefficients were 0.72 , 0.43 and 0.56 respectively. Finally, the authors concluded that this method is highly reliable, accurate, consistent and robust [11].

Salafian et al. proposed an automatic method for segmentation of choroid in neutrosophic space on EDI-OCT images. At this study, 32 EDI-OCT images from 11 people were automatically segmented and compared with man- 
ual segmentations. Applying any process on image in neutrosophic approach was modeled by three sets including indeterminacy, false and true sets. First of all, each image was transformed to the neutrosophic space; second, in order to detect RPE layer, the weights between two nodes were calculated and the Dijkstra algorithm was applied. Finally, the choroidal layer was segmented by similar approach used for RPE, based on applying homomorphic filter and gamma correction to false set and RPE localization. The results showed the unsigned error of $25.3 \mu \mathrm{m}$ (6.55 pixels) for prepapillary images and $12.9 \mu \mathrm{m}$ (3.34 pixels) for macular images. The advantage of this study is that this method is novel on prepapillary data while other published works are focused on macular data [67].

Masood et al. presented an automatic method for segmentation of choroidal layer in OCT images, utilizing a series of morphological operations and deep learning. They segmented the choroidal layer using a deep learning approach and the BM utilizing a series of morphological operations. At this study, the total 525 OCT images of 21 individuals were used as each individual had 25 OCT scans in which the data of 10 people (250 images) was used for testing and the data of 11 individuals (275 images) was used for training. The average dice coefficient was $97.35 \%$ with a standard deviation of $2.3 \%$ for 250 tested images, showing that there is a well stability between proposed algorithm and manual segmentations. Moreover, the obtained results in this study demonstrate that this method considerably reduces the error rate in comparison with the other methods [68].

George et al. proposed a new method for automatic segmentation of the choroidal layer in OCT images. The rotating kernel transformation (RKT) filter was used for image enhancement then a multi-level contour evolution based on Chan Vese method was used for choroidal segmentation. The used data set was the same with Danesh et al. [8] which had 589
OCT images in 19 volumes and each volume contains 31 OCT images corresponding to one eye. The mean error (ME) and mean absolute error (MAE) for BM and CSI between the automatic and manual segmentations were $0.15 \pm 0.8$ pixels, $1.78 \pm 1.3$ pixels, $0.48 \pm 3.8$ pixels, and $4.7 \pm 3.2$ pixels, respectively. This method showed high correlation with manual segmentations and good consistency and accuracy. It can be concluded that this presented method is efficient and simple without any need to training [69].

All of recently published methods have been briefly mentioned at Table 1 .

\section{Evaluation metrics}

Generally, the performance of the choroidal segmentation algorithms was evaluated with manual segmentation accomplished by an expert clinician. Some of the popular metrics which have been used for evaluation of choroidal layer segmentations are as follows: volume difference (VD), thickness difference (TD), correlation coefficients (CC), mean squared error (MSE), mean absolute error (MAE), Dice's coefficient (DC), mean unsigned border positioning errors (MUBPE), mean signed border positioning errors (MSBPE), absolute border position difference (ABPD), mean border position difference (MBPD), accuracy, mean overlap ratio, and unsigned error.

One of the statistical metrics for comparing the similarity of two samples is Dice's coefficient which was presented by Thorvald Sørensen and Lee Raymond Dice [70] in 1948 and 1945, respectively. Its original formula was considered to be applied to binary data. It is defined as bellow, (given two sets, $\mathrm{X}$ and $\mathrm{Y}$ ):

$$
D S C=\frac{2 \times|X \cap Y|}{|X|+|Y|}
$$

When applied to Boolean data using the definition of false negative (FN), false positive (FP) and true positive (TP), it can be written as: 
Table 1: Available choroidal segmentation methods

\begin{tabular}{|c|c|c|c|c|c|}
\hline & Authors & Purpose & Samples & Methods & Results \\
\hline 1 & $\begin{array}{l}\text { Vedran Kajić } \\
\text { et al., [50] } \\
(2012)\end{array}$ & $\begin{array}{l}\text { Automatic choroidal } \\
\text { segmentation of normal } \\
\text { \& pathologic eyes in } \\
\text { SD-OCT images. }\end{array}$ & $\begin{array}{l}871 \text { B-scans from } 12 \\
\text { adult eyes. }\end{array}$ & $\begin{array}{l}\text { Machine learning using } \\
\text { stochastic modeling. } \\
\text { Neural network, convex } \\
\text { hull, active appearance } \\
\text { model and Dijkstra's } \\
\text { shortest path. }\end{array}$ & $\begin{array}{c}\text { (Fraction of misclassified } \\
\text { pixels.) Average error = } \\
13 \%\end{array}$ \\
\hline 2 & $\begin{array}{c}\text { Teresa } \\
\text { Torzicky } \\
\text { et al., [51] } \\
(2012)\end{array}$ & $\begin{array}{l}\text { Automatically choroidal } \\
\text { thickness segmentation } \\
\text { from polarization sensi- } \\
\text { tive OCT (PS-OCT). }\end{array}$ & $\begin{array}{c}5 \text { healthy subjects } \\
\text { age from } 25 \text { to } 54 \\
\text { years. }\end{array}$ & $\begin{array}{l}\text { For RPE segmentation } \\
\text { used depolarization, } \\
\text { and CSI: using the bire- } \\
\text { fringence of the sclera. }\end{array}$ & $\begin{array}{c}\text { Standard deviation of } \\
\text { thickness measurement }= \\
18.3 \mu \mathrm{m} .\end{array}$ \\
\hline 3 & $\begin{array}{l}\text { Jing Tian } \\
\text { et al., [13] } \\
\text { (2012) }\end{array}$ & $\begin{array}{l}\text { The fast and accurate } \\
\text { algorithm that could } \\
\text { measure the choroidal } \\
\text { thickness automatically } \\
\text { in EDI-OCT images. }\end{array}$ & $\begin{array}{l}45 \text { B-scans one each } \\
\text { from } 45 \text { healthy adult } \\
\text { subjects. }\end{array}$ & $\begin{array}{l}\text { Gradient based graph } \\
\text { search (dynamic pro- } \\
\text { graming). }\end{array}$ & $\begin{array}{c}\text { Mean DC }=90.5 \% \text { (SD } \\
3 \%) .\end{array}$ \\
\hline 4 & $\begin{array}{l}\text { Li Zhang } \\
\text { et al., [54] } \\
\text { (2012) }\end{array}$ & $\begin{array}{l}\text { Quantification of } \\
\text { choriocapillaris-equiv- } \\
\text { alent thickness of the } \\
\text { macula and choroidal } \\
\text { vasculature thickness } \\
\text { and choroidal vessels } \\
\text { segmentation, on 3D } \\
\text { SD-OCT images. }\end{array}$ & 24 normal subjects & $\begin{array}{l}\text { Graph based multilayer } \\
\text { segmentation method. }\end{array}$ & $\begin{array}{c}\text { Average choriocapillaris } \\
\text { equivalent thickness }=23.1 \\
\mu \mathrm{m} \text { Average thickness of } \\
\text { the choroidal vasculature } \\
\text { in normal subjects }=172.1 \\
\begin{array}{c}\mu \mathrm{m} \text { Dice coefficient }=0.78 \\
\pm 0.08\end{array}\end{array}$ \\
\hline 5 & $\begin{array}{l}\text { Zhihong Hu } \\
\text { et al., [55] } \\
\text { (2013) }\end{array}$ & $\begin{array}{l}\text { Automatically identify } \\
\text { the choroidal layer in } \\
\text { SD-OCT volume } \\
\text { scans and compare its } \\
\text { performance to manual } \\
\text { delineation. }\end{array}$ & $\begin{array}{l}37 \text { B-scans per eye, } \\
20 \text { eyes from } 20 \\
\text { healthy and } 10 \text { eyes } \\
\text { from } 10 \text { non-neo- } \\
\text { vascular AMD adult } \\
\text { subjects. }\end{array}$ & $\begin{array}{l}\text { Gradient based mul- } \\
\text { tistage graph search } \\
\text { approach. }\end{array}$ & 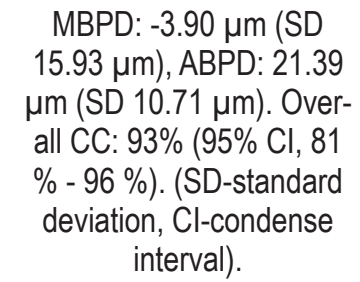 \\
\hline
\end{tabular}

Comparison of the subfoveal choroidal thickSieun Lee ness measurements 6 et al., [56] by expert raters and an (2013) automated algorithm in EDI-OCT images of eyes with nonneovascular AMD.

\begin{tabular}{ccc}
\hline & Huiqi Lu & Automated Segmenta- \\
et al., [12] & tion of the choroid in \\
& (2013) & retinal OCT images.
\end{tabular}

David Alonso-Caneiro et al., [6] (2013) Automatic segmentation scans of 104 healthy of choroidal thickness in subjects and 90 adult EDI-OCT images.
88 eyes of 44 patients suffering from bilateral nonneovascular AMD and age above 55 .

30 adult subjects with diabetes. One eye randomly selected in each subject.
Three dimensional graph-cut algorithm.

Gradient based graph search, (dynamic programing).
Mean subfoveal choroidal thickness $=246 \pm 63 \mu \mathrm{m}$

(the first rater), $214 \pm$ 68(the second rater), and $209 \pm 53$ (the automated algorithm).

\section{Mean DC: $92.7 \%$ (SD $3.6 \%)$.}

The mean absolute error (MAE) was $12.6 \mu \mathrm{m}$ (SD $9.00 \mu \mathrm{m})$ for pediatric and $16.27 \mu \mathrm{m}$ (SD $11.48 \mu \mathrm{m})$ for adult, also the mean dice coefficient (mean DC) was $97.3 \%$ (SD 1.5\%) for pediatric and $96.7 \%$ (SD $2.1 \%)$ for adult. 


\begin{tabular}{|c|c|c|c|c|c|}
\hline & Authors & Purpose & Samples & Methods & Results \\
\hline 9 & $\begin{array}{l}\text { Danesh et } \\
\text { al., [8] (2014) }\end{array}$ & $\begin{array}{l}\text { Segmentation of } \\
\text { choroidal boundary in } \\
\text { EDI-OCTs. }\end{array}$ & $\begin{array}{l}100 \text { B-scans from } \\
10 \text { eyes of } 6 \text { healthy } \\
\text { adult subjects. }\end{array}$ & $\begin{array}{l}\text { dynamic programming, } \\
\text { largest gradient, wavelet } \\
\text { features and Gaussian } \\
\text { mixture model }\end{array}$ & $\begin{array}{c}\text { MUBPE: } 9.79 \text { pixels (SD } \\
3.29 \text { pixels), MSBPE: } 5.77 \\
\text { pixels (SD } 2.77 \text { pixels). }\end{array}$ \\
\hline 10 & $\begin{array}{l}\text { Bianca S. } \\
\text { Gerendas } \\
\text { et al., [57] } \\
(2014)\end{array}$ & $\begin{array}{l}\text { Automatically mea- } \\
\text { surement of choroidal } \\
\text { thickness in SD-OCT } \\
\text { images. }\end{array}$ & $\begin{array}{l}284 \text { eyes of } 142 \\
\text { patients with clinically } \\
\text { significant DME and } \\
20 \text { controls. }\end{array}$ & $\begin{array}{l}\text { lowa reference algo- } \\
\text { rithm (graph-based). }\end{array}$ & $\begin{array}{c}\text { Total choroidal thickness } \\
\text { is significantly reduced } \\
\text { in DME (175 } \pm 23 \mu \mathrm{m} ; \mathrm{P} \\
[0.0016]) \text { and nonedema- } \\
\text { tous fellow eyes ( } 177 \pm 20 \\
\mu \mathrm{m} ; \mathrm{P}[0.009]) \text { of patients } \\
\text { compared with healthy } \\
\text { control eyes (190 } \pm 23 \\
\mu \mathrm{m}) \text {. }\end{array}$ \\
\hline 11 & $\begin{array}{l}\text { N. Srinath } \\
\text { et al., [58] } \\
(2014)\end{array}$ & $\begin{array}{l}\text { Automated detection of } \\
\text { choroid boundary and } \\
\text { vessels in OCT Images. }\end{array}$ & $\begin{array}{l}\text { OCT images of the } \\
\text { posterior part of the } \\
\text { eye taken with } 30 \mu \mathrm{m} \\
\text { separation. }\end{array}$ & $\begin{array}{c}\text { Structural similar- } \\
\text { ity \& adaptive Hessian } \\
\text { analysis. }\end{array}$ & $\begin{array}{l}{ }^{\bar{s}}{ }^{200} \\
\text { length of the image }\end{array}$ \\
\hline 12 & $\begin{array}{l}\text { Kiran Kumar } \\
\text { Vuppara- } \\
\text { boina et al., } \\
\text { [59] (2015) }\end{array}$ & $\begin{array}{l}\text { Automated Estimation } \\
\text { of choroidal thickness } \\
\text { distribution on SD-OCT } \\
\text { images. }\end{array}$ & $\begin{array}{l}97 \text { B-scans per eye, } \\
\text { one eye randomly } \\
\text { chosen per subject, } \\
5 \text { healthy adult } \\
\text { subjects. }\end{array}$ & $\begin{array}{l}\text { Structural similarity } \\
\text { index, tensor voting, } \\
\text { and eigenvalue analysis } \\
\text { of the Hessian matrix. }\end{array}$ & $\begin{array}{c}19.15 \mu \mathrm{m}(\mathrm{SD} 15.98 \\
\mu \mathrm{m}) \text { Mean CC = 99.64\% } \\
(\mathrm{SD} 0.27 \%) \text { Mean DC = } \\
95.47 \% \text { (SD 1.73\%) Mean } \\
\text { absolute volume difference } \\
=0.3046 \mathrm{~mm}^{3} .\end{array}$ \\
\hline 13 & $\begin{array}{l}\text { Qiang Chen } \\
\text { et al., [48] } \\
(2015)\end{array}$ & $\begin{array}{c}\text { Automated choroid } \\
\text { segmentation, including } \\
\text { the segmentation of BM } \\
\text { and CSI from SD-OCT } \\
\text { images. }\end{array}$ & $\begin{array}{c}212 \text { HD-OCT images } \\
\text { from } 110 \text { eyes in } 66 \\
\text { patients. }\end{array}$ & $\begin{array}{l}\text { Thresholding, gradual } \\
\text { intensity distance, graph } \\
\text { min cut-max-flow and } \\
\text { the energy minimization } \\
\text { technique. }\end{array}$ & $\begin{array}{c}\mathrm{CC}=0.970 \mathrm{TD}[\mu \mathrm{m}]=6.72 \\
\pm 8.26\end{array}$ \\
\hline 14 & $\begin{array}{l}\text { Fei Shi et al., } \\
\text { [60] (2016) }\end{array}$ & $\begin{array}{l}\text { Segmentation of the } \\
\text { choroid from 1- } \mu \text { m wide } \\
\text { view swept source OCT. }\end{array}$ & 32 normal eyes. & $\begin{array}{l}\text { 3-D graph search (with } \\
\text { gradient-based cost). }\end{array}$ & $\begin{array}{c}\text { mean } T D=20.64 \pm 4.16 \\
\mu m \text { mean } D S C=93.17 \pm \\
1.30 \%\end{array}$ \\
\hline 15 & $\begin{array}{l}\text { Michael D. } \\
\text { Twa et al., } \\
\text { [61] (2016) }\end{array}$ & $\begin{array}{l}\text { A new image segmen- } \\
\text { tation method to quan- } \\
\text { tify choroid thickness } \\
\text { compared to manual } \\
\text { segmentation. }\end{array}$ & $\begin{array}{l}30 \text { young adults } \\
\text { (24 } \pm 2 \text { years), } \\
\text { predominantly female } \\
\text { (19/30), A total of } 180 \\
\text { B-scan images were } \\
\text { analyzed from the left } \\
\text { eye of each subject. }\end{array}$ & $\begin{array}{c}\text { Graph theory, dy- } \\
\text { namic programming, \& } \\
\text { wavelet-based texture } \\
\text { analysis. }\end{array}$ & $\begin{array}{l}\text { TD (Manual-Auto) Central } \\
\text { (fovea) }=4 \pm 5 \mu \mathrm{m}(P \\
=0.10) \text { Inferior }\left(12.5^{\circ}\right. \\
\text { below fovea) }=-1 \pm 6 \mu \mathrm{m} \\
(P=0.60) \text { Superior }\left(12.5^{\circ}\right. \\
\text { above fovea) }=8 \pm 5 \mu \mathrm{m} \\
(P=0.005)\end{array}$ \\
\hline 16 & $\begin{array}{l}\text { Xiaodan Sui } \\
\text { et al., [9] } \\
\text { (2017) }\end{array}$ & $\begin{array}{l}\text { Choroid segmentation } \\
\text { from optical coherence } \\
\text { tomography. }\end{array}$ & $\begin{array}{c}912 \text { OCT B-scans } \\
\text { from both } 42 \text { normal } \\
\text { subjects and } 31 \\
\text { patients diagnosed } \\
\text { with macular edema, } \\
\text { aged between } 34 \text { and } \\
68 \text { years old. }\end{array}$ & $\begin{array}{l}\text { Graph-Edge weights } \\
\text { learned from deep } \\
\text { convolutional neural } \\
\text { networks. }\end{array}$ & $\begin{array}{c}\text { Mean Squared Error } \\
\left({ }^{*} 1000\right)=5.2 \text { Mean Abso- } \\
\text { lute Error }=8.0 \text { thickness } \\
\text { difference }=8.5\end{array}$ \\
\hline 17 & $\begin{array}{l}\text { Q. Chen } \\
\text { et al., [62] } \\
(2017)\end{array}$ & $\begin{array}{l}\text { Automatically segmen- } \\
\text { tation of choroid from } \\
\text { (3D-SD-OCT) images. }\end{array}$ & $\begin{array}{l}5248 \text { SD-OCT B- } \\
\text { scan images from } 41 \\
\text { eyes (or cubes). }\end{array}$ & $\begin{array}{l}\text { Three-dimensional (3D) } \\
\text { graph search. }\end{array}$ & $\begin{array}{c}\text { Volume difference (VD) } \\
{\left[\mu \mathrm{m}^{3} \times 10^{3}\right]=-1.96 \pm 4.42} \\
\text { Thickness difference }(\mathrm{TD}) \\
{[\mu \mathrm{m}]=-3.53 \pm 7.99 \text { Cor- }} \\
\text { relation coefficients }(\mathrm{CC}) \\
=0.9175\end{array}$ \\
\hline
\end{tabular}


Reza Alizadeh Eghtedar, et al

\begin{tabular}{|c|c|c|c|c|c|}
\hline & Authors & Purpose & Samples & Methods & Results \\
\hline 18 & $\begin{array}{l}\text { Javier Maz- } \\
\text { zaferri et al., } \\
\text { [63] (2017) }\end{array}$ & $\begin{array}{c}\text { A new automatic } \\
\text { algorithm based on } \\
\text { graph theory developed } \\
\text { to detect the boundar- } \\
\text { ies of choroid on OCT } \\
\text { images. }\end{array}$ & 280 patients & Graph based method & $\begin{array}{c}\text { The mean success- } \\
\text { ful fraction was always } \\
\text { above } 96 \% \text { with standard } \\
\text { deviation below } 5 \% \text {, for all } \\
\text { patient cohorts. }\end{array}$ \\
\hline 19 & $\begin{array}{l}\text { Al-Bander } \\
\text { et al., [64] } \\
(2017)\end{array}$ & $\begin{array}{l}\text { Presentation of an ac- } \\
\text { curate and fast method } \\
\text { for choroidal segmen- } \\
\text { tation on EDI-OCT } \\
\text { images. }\end{array}$ & 169 EDI-OCT images & $\begin{array}{c}\text { Deep learning algorithm } \\
\text { (convolutional neural } \\
\text { network) }\end{array}$ & $\begin{array}{c}\text { Accuracy }=98.01 \% \text { DC }= \\
89.76 \%\end{array}$ \\
\hline 20 & $\begin{array}{l}\text { Chen et al., } \\
\text { [65] (2017) }\end{array}$ & $\begin{array}{l}\text { Automatic segmenta- } \\
\text { tion of choroidal layer } \\
\text { on EDI-OCT images of } \\
\text { patients with AMD. }\end{array}$ & $\begin{array}{l}62 \text { EDI-OCT images } \\
\text { of AMD patients, } \\
\text { which has been } \\
\text { manually segmented. }\end{array}$ & $\begin{array}{l}\text { A learning based } \\
\text { method, using convolu- } \\
\text { tional neural networks. }\end{array}$ & $\begin{array}{c}\text { mean Dice coefficient }=82 \\
\pm 1 \%\end{array}$ \\
\hline 21 & $\begin{array}{l}\text { Wang et al., } \\
\text { [66] (2017) }\end{array}$ & $\begin{array}{l}\text { An automatic technique } \\
\text { for choroidal layer seg- } \\
\text { mentation in 3D OCT } \\
\text { images. }\end{array}$ & $\begin{array}{l}\text { Thirty 3D OCT scans } \\
\text { of thirty healthy } \\
\text { subjects which ages } \\
\text { were between } 20 \text { to } \\
85 \text { years. }\end{array}$ & $\begin{array}{l}\text { 3D nonlinear anisotropic } \\
\text { diffusion filter for image } \\
\text { enhancement and the } \\
\text { level set and Markov } \\
\text { random field methods } \\
\text { for approximation of the } \\
\text { boundary of choroid. }\end{array}$ & $\begin{array}{c}\text { mean signed difference }= \\
1.59 \pm 1.65 \text { pixels mean } \\
\text { unsigned difference }=2.17 \\
\pm 1.77 \text { pixels mean Dice's } \\
\text { coefficient }=90 \pm 4 \%\end{array}$ \\
\hline 22 & $\begin{array}{l}\text { Hussain } \\
\text { et al., [11] } \\
(2018)\end{array}$ & $\begin{array}{l}\text { Presented a method for } \\
\text { segmentation of choroid } \\
\text { from EDI-OCT images. }\end{array}$ & $\begin{array}{l}\text { This method was ap- } \\
\text { plied on } 190 \text { B-scans } \\
\text { of } 10 \text { subjects. }\end{array}$ & $\begin{array}{l}\text { Dijkstra's shortest path } \\
\text { algorithm }\end{array}$ & $\begin{array}{c}\text { Mean RMSE }=7.71 \pm 6.29 \\
\text { pixels } C C=0.76\end{array}$ \\
\hline 23 & $\begin{array}{l}\text { Salafian } \\
\text { et al., [67] } \\
(2018)\end{array}$ & $\begin{array}{l}\text { An automatic method } \\
\text { for segmentation of } \\
\text { choroid in neutrosophic } \\
\text { space on EDI-OCT } \\
\text { images. }\end{array}$ & $\begin{array}{l}32 \text { EDI-OCT images } \\
\text { from } 11 \text { people. }\end{array}$ & $\begin{array}{l}\text { Dijkstra's algorithm in } \\
\text { neutrosophic space }\end{array}$ & $\begin{array}{c}\text { Unsigned error of } 25.3 \mu \mathrm{m} \\
\text { (6.55 pixels) for prepapil- } \\
\text { lary images and } 12.9 \mu \mathrm{m} \\
\text { (3.34 pixels) for macular } \\
\text { images. }\end{array}$ \\
\hline 24 & $\begin{array}{l}\text { Masood } \\
\text { et al., [68] } \\
(2019)\end{array}$ & $\begin{array}{l}\text { An automatic method } \\
\text { for segmentation of } \\
\text { choroidal layer in OCT } \\
\text { images. }\end{array}$ & $\begin{array}{l}525 \text { OCT images of } \\
21 \text { individuals (each } \\
\text { individual had } 25 \\
\text { OCT scans) }\end{array}$ & $\begin{array}{l}\text { A series of morphologi- } \\
\text { cal operations and deep } \\
\text { learning }\end{array}$ & $\begin{array}{c}\text { The average dice coef- } \\
\text { ficient }=97.35 \% \text { standard } \\
\text { deviation }=2.3 \%\end{array}$ \\
\hline 25 & $\begin{array}{l}\text { George } \\
\text { et al., [69] } \\
(2019)\end{array}$ & $\begin{array}{l}\text { A new method in } \\
\text { order to segment the } \\
\text { choroidal layer in OCT } \\
\text { images. }\end{array}$ & $\begin{array}{l}\text { The used data set } \\
\text { was the same with } \\
\text { Danesh et al., [8] } \\
\text { which had } 589 \\
\text { OCT images in } 19 \\
\text { volumes and each } \\
\text { volume had } 31 \text { OCT } \\
\text { images correspond- } \\
\text { ing to one eye. }\end{array}$ & $\begin{array}{l}\text { Rotating kernel trans- } \\
\text { formation (RKT) filter } \\
\text { for image enhancement } \\
\text { and multi-level contour } \\
\text { evolution based on } \\
\text { Chan Vese method for } \\
\text { choroidal segmentation. }\end{array}$ & $\begin{array}{c}\text { Mean error of } \mathrm{BM}=0.15 \pm \\
0.8 \text { pixels Mean absolute } \\
\text { error of } \mathrm{BM}=1.78 \pm 1.3 \\
\text { pixels Mean error of } \mathrm{CSI} \\
=0.48 \pm 3.8 \text { pixels Mean } \\
\text { absolute error of CSI }=4.7 \\
\pm 3.2 \text { pixels }\end{array}$ \\
\hline
\end{tabular}

PS-OCT: Polarization sensitive optical coherence tomography, RPE: Retinal Pigment Epithelium, CSI: choroidal-scleral interface, EDI-OCT: Enhanced Depth Imaging Optical Coherence Tomography, DC: dice coefficient, SD-OCT: Spectral-Domain Optical Coherence Tomography, AMD: Age-related Macular Degeneration, MBPD: mean border position difference, CC: Correlation coefficients, MAE: Mean absolute error, MUBPE: Mean unsigned border positioning errors, DME: Diabetic Macular Edema, HDOCT: High-Definition Optical Coherence Tomography, TD: Thickness difference, RMSE: Root-mean-square error, BM: Bruch's membrane

$$
D S C=\frac{2 T P}{2 T P+F P+F N}
$$

A statistical relationship between two vari- ables is called, correlation coefficient (CC). The variables may be two components of a multivariate random variable with a known distribution or two columns of a given data set 
of observations, often called a sample. There are also several types of correlation coefficients, each with their own definition. All of them range from -1 to +1 , where -1 and +1 show the strongest possible disagreement and possible agreement. Correlation coefficients as analysis tools contain certain problems such as the possibility of incorrectly being used to infer a causal relationship between the variables and the propensity of some types distorted by outliers [71]. The correlation between two random variables $\mathrm{u}$ and $\mathrm{v}$ is defined as:

$$
C C=\frac{n\left(\sum u v\right)-\left(\sum u\right)\left(\sum v\right)}{\sqrt{\left[n \sum u^{2}-\left(\sum u\right)^{2}\right]\left[n \sum v^{2}-\left(\sum v\right)^{2}\right]}}
$$

The mean squared error (MSE) of an estimator in statistics, measuring the mean of the squares of the errors, is the difference between the estimator and what is estimated [72], which is always non-negative, also a measure of the quality of an estimator, and the values closer to zero are better. If $\mathrm{Y}$ is the vector of observed values of the variable predicted and $\hat{Y}$ is a vector of $\mathrm{n}$ predictions, the MSE of the predictor will be as bellow:

$$
M S E=\frac{1}{n} \sum_{i=1}^{n}\left(Y_{i}-\widehat{Y}_{i}\right)^{2}
$$

The measure of difference between two continuous variables in statistics is called the mean absolute error (MAE). It is the average horizontal distance between each point and the line $\mathrm{Y}=\mathrm{X}$, and also the MAE is the average vertical distance between each point and the line $\mathrm{Y}=\mathrm{X}$, defined as bellow [73]:

$$
M A E=\frac{\sum_{i=1}^{n}\left|y_{i}-x_{i}\right|}{n}=\frac{\sum_{i=1}^{n}\left|e_{i}\right|}{n}
$$

Also, another metric used for evaluation is accuracy and formula is [64]:

$$
\operatorname{Acc}(\%)=\frac{T P+T N}{T P+T N+F P+F N} \times 100
$$

Where; TP: True Positive, TN: True Negative, FP: False Positive, and FN: False Nega- tive.

The TD and overlap ratio measure the choroid area difference and their mean values are computed as following [48]:

$$
\begin{aligned}
& \overline{T D}(M ; N)=\frac{1}{j} \sum_{j=1}^{j} \frac{1}{n} \sum_{r=1}^{n}\left(T M_{j}^{r}-T N_{j}^{r}\right) \\
& \overline{\text { Overlap }}(M ; N)=\frac{1}{j} \sum_{j=1}^{j} \frac{M_{j} \cap N_{j}}{M_{j} \cup N_{j}}
\end{aligned}
$$

Where $j$ shows the number of $\mathrm{B}$-scan. $\mathrm{M}_{\mathrm{j}}^{\mathrm{r}}$ and $\mathrm{N}_{\mathrm{j}}{ }^{\mathrm{r}}$ show the coordinates of the $\mathrm{r}^{\text {th }}$ column in the axial direction of B-scan $j$, produced by the method $\mathrm{M}$ and the grader $\mathrm{N}$, respectively. $\mathrm{TM}_{\mathrm{j}}{ }^{\mathrm{r}}$ and $\mathrm{TN}_{\mathrm{j}}{ }_{\mathrm{r}}^{\mathrm{r}}$ show the choroidal thicknesses of the $\mathrm{r}^{\text {th }}$ column in the axial direction of Bscan $j$, produced by the method $\mathrm{M}$ and the grader $N$, respectively. $M_{j}$ and $N_{j}$ show the regions inside the segmented choroid boundary of B-scan $j$. The operator $\cup$ and $\cap$ show union and intersection, respectively.

Among the proposed metrics, Dice, used very often, is biased by the thickness of the tissue which may not be used in comparing "thicker and thinner" choroids. One another popular metric for evaluating the automatic choroidal segmentation is correlation coefficient that is easy to interpret and work out, but it can only measure linear relationships and the results will not be accurate if the relationship is not linear. The most of the reviewed studies reported the mean thickness differences as evaluation metrics which were more advantageous than the other metrics because it is not biased by the thickness of the tissue and can be useful in comparing "thicker and thinner" choroids.

\section{Discussion}

This paper has attempted to cover a wide and detailed analysis of the most recent automatic choroidal segmentation techniques and reviewed the most effective and innovative methods of automatic choroidal segmentation. Advantages and disadvantages of each meth- 
od were featured, including available metrics reported by the authors. However, despite the recently done efforts, there are still chances for more improvements. Besides, the automatic segmentation methods would be more accurate than the manual segmentation of choroid. In order to extract the choroidal thickness, there is a need to expand automatic image segmentation techniques.

Since all methods have been applied to different data, it is impossible to compare accurately and quantitatively between different methods, therefore, only the qualitative comparison of the results of each method is considered. According to the results, it seems that methods based on graph theory have better and more acceptable results than other methods since using the graph theory and dynamic programming can provide accurate, repeatable and rapid quantitative measurements of choroidal thickness [61]. The techniques based on graph searching are widely used for segmentation of choroidal boundaries $[6,8,9,12,13$, 54-57, 60-63, 67] and the comparison of maintained results such as DSC in Table 1 generally shows great superiority of this method $[6$, $12,13,54,60]$ over other proposed methods $[59,64,65,68]$.

A graph searching algorithm was performed accurately if appropriate graph-edge weights is assigned and in comparison with dynamic programming method and traditional methods of boundary detection, the graph search method contains two advantages, as follows: (1) dynamic programming method and the traditional boundary detection methods are mainly dependent on gradient of image. In HD-OCT images, the gradient of CSI borders is weaker than choroidal vessels, thus choroid vessels make these methods difficult to detect CSI boundaries. (2) It merges smoothness constrains and neighbor information to segment CSI boundary, constructing the inter-arcs according to neighbor columns and intra-arcs in the graph from one vertex to next vertex in each column. In dynamic programming meth- ods, 8 or 4-neighborhoods are used to construct a graph, without considering the column constrains. Besides, all of the methods contain one or more of the following disadvantages: they do not exhibit robustness in varied and noisy cases, require manual intermediation of the operator, and only segment the most prominent layers.

\section{Conclusion}

In this paper, we reviewed the available studies for the automatic segmentation of the choroid with a focus on samples, methods, and results of each study. The review of the methods used in the articles indicates that methods based on graph theory are mostly used. The DSC metric generally shows that graph-based methods could perform acceptably in automatic segmentation of the choroid and have significant superiority over other proposed methods. Finally, if an automatic choroidal segmentation method properly was designed, not only it can be used in quantitative studies of the choroid, but also it can help the ophthalmologists as an effective tool in diagnosing choroidal related eye diseases.

\section{Authors' Contribution}

Peyman A and Akhlaghi A, made substantial contributions to the design of the study. Eghtedar RA and Esmaeili M, drafted and critically reviewed the manuscript. Rasta $\mathrm{SH}$, was responsible for the overall supervision of the work, as a corresponding author. All authors read and approved the final manuscript.

\section{Conflict of Interest}

None

\section{References}

1. Esmaeili M, Dehnavi AM, Rabbani H. 3D curvelet-based segmentation and quantification of drusen in optical coherence tomography images. J Electr Comput Eng. 2017;2017:12. doi: $10.1155 / 2017 / 4362603$.

2. Esmaeili M, Dehnavi AM, Rabbani $H$, Hajizadeh F. Speckle noise reduction in optical coherence tomography using two-dimensional curvelet- 
Automatic Segmentation Methods of Choroidal Layer

based dictionary learning. J Med Signals Sens. 2017;7(2):86. PubMed PMID: 28553581. PubMed PMCID: PMC5437767.

3. Mahsa P, Seyed Hossein R, Alireza J. Automatic detection of retinal exudates in fundus images of diabetic retinopathy patients. J Anal Res Clin Med. 2016;4(2):104-9. doi: 10.15171/jarcm.2016.017.

4. Rasta SH, Nikfarjam S, Javadzadeh A. Detection of retinal capillary nonperfusion in fundus fluorescein angiogram of diabetic retinopathy. Biolmpacts. 2015;5(4):183. doi: 10.15171/bi.2015.27. PubMed PMID: 26929922. PubMed PMCID: PMC4769788.

5. Rasta SH, Partovi ME, Seyedarabi H, Javadzadeh A. A comparative study on preprocessing techniques in diabetic retinopathy retinal images: illumination correction and contrast enhancement. J Med Signals Sens. 2015;5(1):40. PubMed PMID: 25709940. PubMed PMCID: PMC4335144.

6. Alonso-Caneiro D, Read SA, Collins MJ. Automatic segmentation of choroidal thickness in optical coherence tomography. Biomed Opt Express. 2013;4(2):2795-812. doi: 10.1364/BOE.4.002795. PubMed PMID: 24409381. PubMed PMCID: PMC3862153.

7. Duan L, Hong YJ, Yasuno Y. Automated segmentation and characterization of choroidal vessels in high-penetration optical coherence tomography. Opt Express. 2013;21(13):15787-808. doi: 10.1364/OE.21.015787. PubMed PMID: 23842365

8. Danesh H, Kafieh R, Rabbani H, Hajizadeh F. Segmentation of choroidal boundary in enhanced depth imaging OCTs using a multiresolution texture based modeling in graph cuts. Comput Math Methods Med. 2014;2014:1-9. doi: 10.1155/2014/479268. PubMed PMID: 24672579. PubMed PMCID: PMC3942333.

9. Sui X, Zheng Y, Wei B, Bi H, Wu J, Pan X, Yin $Y$, Zhang $S$. Choroid segmentation from optical coherence tomography with graph-edge weights learned from deep convolutional neural networks. Neurocomputing. 2017;237:332-41. doi: 10.1016/j.neucom.2017.01.023.

10. Leitgeb R, Hitzenberger CK, Fercher AF. Performance of fourier domain vs. time domain optical coherence tomography. Opt Express. 2003;11(8):889-94. doi: 10.1364/OE.11.000889. PubMed PMID: 19461802.

11. Hussain MA, Bhuiyan A, Ishikawa $H$, Smith RT, Schuman JS, Kotagiri R. An automated method for choroidal thickness measurement from Enhanced Depth Imaging Optical Coherence Tomography images. Comput Med Imaging and
Graph. 2018;63:41-51. doi: 10.1016/j.compmedimag.2018.01.001.

12. Lu H, Boonarpha N, Kwong MT, Zheng Y. Automated segmentation of the choroid in retinal optical coherence tomography images. 35th Annual International Conference of the IEEE Engineering in Medicine and Biology Society (EMBC). Osaka, Japan: EEE; 2013. p. 5869-72. doi: 10.1109/ EMBC.2013.6610887.

13. Tian J, Marziliano P, Baskaran M, Tun TA, Aung T. Automatic measurements of choroidal thickness in EDI-OCT images. Annu Int Conf IEEE Eng Med Biol Soc. 2012;2012:5360-3. doi: 10.1109/ EMBC.2012.6347205. PubMed PMID: 23367140.

14. Wu L, Alpizar-Alvarez N. Choroidal imaging by spectral domain-optical coherence tomography. Taiwan J Ophthalmol. 2013;3(1):3-13. doi: 10.1016/j.tjo.2013.01.003.

15. Manjunath V, Taha M, Fujimoto JG, Duker JS. Choroidal Thickness in Normal Eyes Measured Using Cirrus HD Optical Coherence Tomography. Am J Ophthalmol. 2010;150(3):325-9. doi: 10.1016/j. ajo.2010.04.018. PubMed PMID: 20591395. PubMed PMCID: PMC2926223.

16. Margolis R, Spaide RF. A Pilot Study of Enhanced Depth Imaging Optical Coherence Tomography of the Choroid in Normal Eyes. Am Journal of Ophthalmology. 2009;147(5):811-5. doi: 10.1016/j. ajo.2008.12.008. PubMed PMID: 19232559.

17. Ouyang Y, Heussen FM, Mokwa N, Walsh AC, et al. Spatial Distribution of Posterior Pole Choroidal Thickness by Spectral Domain Optical Coherence Tomography. Investig Ophthalmol Vis Sci. 2011;52(9):7019-26. doi: 10.1167/iovs.11-8046. PubMed PMID: 21810980. PubMed PMCID: PMC3176017.

18. Usui S, Ikuno Y, Miki A, Matsushita K, Yasuno $\mathrm{Y}$, Nishida K. Evaluation of the choroidal thickness using high-penetration optical coherence tomography with long wavelength in highly myopic normal-tension glaucoma. Am J Ophthalmol. 2012;153(1):10-6. doi: 10.1016/j.ajo.2011.05.037. PubMed PMID: 21864827.

19. Broekhuyse RM. The lipid composition of aging sclera and cornea. Ophthalmologica. 1975;171(1):82-5. doi: 10.1159/000307448. PubMed PMID: 1124206.

20. Friedman E. A hemodynamic model of the pathogenesis of age-related macular degeneration. Am J Ophthalmol. 1997;124(5):677-82. doi: 10.1016/s0002-9394(14)70906-7. PubMed PMID: 9372722. 
21. Chung SE, Kang SW, Lee JH, Kim YT. Choroidal thickness in polypoidal choroidal vasculopathy and exudative age-related macular degeneration. Ophthalmology. 2011;118(5):840-5. doi: 10.1016/j. ophtha.2010.09.012. PubMed PMID: 21211846.

22. Wood A, Binns A, Margrain T, Drexler W, Považay $B$, Esmaeelpour M, Sheen N. Retinal and choroidal thickness in early age-related macular degeneration. Am J Ophthalmol. 2011;152(6):1030-8. doi: 10.1016/j.ajo.2011.05.021. PubMed PMID: 21851922.

23. Manjunath V, Goren J, Fujimoto JG, Duker JS. Analysis of Choroidal Thickness in Age-Related Macular Degeneration Using Spectral-Domain Optical Coherence Tomography. Am J Ophthalmol. 2011;152(4):663-8. doi: 10.1016/j. ajo.2011.03.008. PubMed PMID: 21708378. PubMed PMCID: PMC3375176.

24. Hidayat AA, Fine BS. Diabetic choroidopathy. Light and electron microscopic observations of seven cases. Ophthalmology. 1985;92(4):512-22. PubMed PMID: 2582331.

25. Esmaeelpour M, Brunner S, Ansari-Shahrezaei S, Nemetz $S$, et al. Choroidal thinning in diabetes type 1 detected by 3-dimensional $1060 \mathrm{~nm}$ optical coherence tomography. Invest Ophthalmol Vis Sci. 2012;53(11):6803-9. doi: 10.1167/iovs.1210314. PubMed PMID: 22952126.

26. Esmaeelpour M, Považay B, Hermann B, Hofer B, et al. Mapping choroidal and retinal thickness variation in type 2 diabetes using three-dimensional 1060-nm optical coherence tomography. Invest Ophthalmol Vis Sci. 2011;52(8):5311-6. doi: 10.1167/iovs.10-6875. PubMed PMID: 21508108.

27. Querques G, Lattanzio R, Querques L, Del Turco C, et al. Enhanced depth imaging optical coherence tomography in type 2 diabetes. Invest Ophthalmol Vis Sci. 2012;53(10):6017-24. doi: 10.1167/ iovs.12-9692. PubMed PMID: 22879414.

28. Regatieri CV, Branchini L, Carmody J, Fujimoto JG, Duker JS. Choroidal thickness in patients with diabetic retinopathy analyzed by spectral-domain optical coherence tomography. Retina. 2012;32(3):563-8. doi: 10.1097/ IAE.0b013e31822f5678. PubMed PMID: 22374157. PubMed PMCID: PMC3393081.

29. Vujosevic S, Martini F, Cavarzeran F, Pilotto E, Midena E. Macular and peripapillary choroidal thickness in diabetic patients. Retina. 2012;32(9):1781-90. doi: 10.1097//AE.0b013e31825db73d. PubMed PMID: 22869022.

30. Nagaoka T, Kitaya N, Sugawara R, Yokota H, Mori F, Hikichi T, Fujio N, Yoshida A. Alteration of choroidal circulation in the foveal region in patients with type 2 diabetes. Br J Ophthalmol. 2004;88(8):1060-3. doi: 10.1136/bjo.2003.035345. PubMed PMID: 15258025. PubMed PMCID: PMC1772269.

31. Lee EJ, Kim TW, Weinreb RN, Park KH, Kim SH, Kim DM. Visualization of the lamina cribrosa using enhanced depth imaging spectral-domain optical coherence tomography. $\mathrm{Am} \mathrm{J} \mathrm{Oph}$ thalmol. 2011;152(1):87-95. doi: 10.1016/j. ajo.2011.01.024. PubMed PMID: 21570046.

32. Park SC, De Moraes CG, Teng CC, et al. Enhanced depth imaging optical coherence tomography of deep optic nerve complex structures in glaucoma. Ophthalmology. 2012;119(1):3-9. doi: 10.1016/j. ophtha.2011.07.012. PubMed PMID: 21978593.

33. Lee EJ, Kim TW, Weinreb RN, Suh MH, Kim H. Lamina cribrosa thickness is not correlated with central corneal thickness or axial length in healthy eyes: central corneal thickness, axial length, and lamina cribrosa thickness. Graefes Arch Clin Exp Ophthalmol. 2013;251(3):847-54. doi: 10.1007/ s00417-012-2145-y. PubMed PMID: 22990581.

34. Park HY, Jeon SH, Park CK. Enhanced depth imaging detects lamina cribrosa thickness differences in normal tension glaucoma and primary openangle glaucoma. Ophthalmology. 2012:119(1):1020. doi: 10.1016/j.ophtha.2011.07.033. PubMed PMID: 22015382.

35. Guyer DR, Yannuzzi LA, Slakter JS, Sorenson JA, Ho A, Orlock D. Digital indocyanine green videoangiography of central serous chorioretinopathy. Arch Ophthalmol. 1994;112(8):1057-62. doi: 10.1001/archopht.1994.01090200063023. PubMed PMID: 8053819.

36. Imamura Y, Fujiwara T, Margolis R, Spaide RF. Enhanced depth imaging optical coherence tomography of the choroid in central serous chorioretinopathy. Retina. 2009;29(10):1469-73. doi: 10.1097/IAE.0b013e3181be0a83. PubMed PMID: 19898183.

37. Jirarattanasopa P, Ooto S, Tsujikawa A, Yamashiro $\mathrm{K}$, et al. Assessment of macular choroidal thickness by optical coherence tomography and angiographic changes in central serous chorioretinopathy. Ophthalmology. 2012;119(8):1666-78. doi: 10.1016/j.ophtha.2012.02.021. PubMed PMID: 22521082.

38. Manjunath V, Fujimoto JG, Duker JS. Evaluation of Choroidal Thickness in Central Serous Chorioretinopathy Using Cirrus HD Optical Coherence Tomography. Retina. 2010;30(8):1320-1. doi: 10.1097/IAE.0b013e3181e798b1. PubMed PMID: 20827146. PubMed PMCID: PMC3355199. 
39. Maruko I, lida T, Sugano Y, Ojima A, Ogasawara M, Spaide RF. Subfoveal choroidal thickness after treatment of central serous chorioretinopathy. Ophthalmology. 2010;117(9):1792-9. doi: 10.1016/j.ophtha.2010.01.023. PubMed PMID: 20472289.

40. Pryds A, Larsen M. Choroidal thickness following extrafoveal photodynamic treatment with verteporfin in patients with central serous chorioretinopathy. Acta Ophthalmol. 2012;90(8):738-43. doi: 10.1111/j.1755-3768.2011.02157.x. PubMed PMID: 21586096.

41. Kim YT, Kang SW, Bai KH. Choroidal thickness in both eyes of patients with unilaterally active central serous chorioretinopathy. Eye. 2011;25(12):163540. doi: 10.1038/eye.2011.258. PubMed PMID: 22020172. PubMed PMCID: PMC3234484.

42. lida T, Kishi S, Hagimura N, Shimizu K. Persistent and bilateral choroidal vascular abnormalities in central serous chorioretinopathy. Retina. 1999;19(6):50812. doi: 10.1097/00006982-199911000-00005. PubMed PMID: 10606450.

43. Kim DY, Silverman RH, Chan RV, Khanifar AA, et al. Measurement of choroidal perfusion and thickness following systemic sildenafil (Viagra(®)). Acta Ophthalmol. 2013;91(2):183-8. doi: 10.1111/j.1755-3768.2011.02305.x. PubMed PMID: 22974308. PubMed PMCID: PMC3528845.

44. Vance SK, Imamura Y, Freund KB. The effects of sildenafil citrate on choroidal thickness as determined by enhanced depth imaging optical coherence tomography. Retina. 2011;31(2):332-5. doi: 10.1097/IAE.0b013e3181eef0ae. PubMed PMID: 20975620.

45. Eliwa TF, Hegazy OS, Mahmoud SS, Almaamon T. Choroidal Thickness Change in Patients With Diabetic Macular Edema. Ophthalmic Surg Lasers Imaging Retina. 2017;48(12):970-7. doi: 10.3928/23258160-20171130-03. PubMed PMID: 29253299.

46. Esen E, Sizmaz S, Demir T, Demirkiran M, Unal I, Demircan N. Evaluation of Choroidal Vascular Changes in Patients with Multiple Sclerosis Using Enhanced Depth Imaging Optical Coherence Tomography. Ophthalmologica. 2016;235(2):6571. doi: 10.1159/000441152. PubMed PMID: 26485541.

47. Sim DA, Keane PA, Mehta H, Fung S, et al, Tufail A. Repeatability and reproducibility of choroidal vessel layer measurements in diabetic retinopathy using enhanced depth optical coherence tomography. Investigative Ophthalmology \& Visual Science. 2013;54(4):2893-901. doi: 10.1167/iovs.12-
11085.

48. Chen Q, Fan W, Niu S, Shi J, Shen H, Yuan S. Automated choroid segmentation based on gradual intensity distance in HD-OCT images. Opt Express. 2015;23(7):8974-94. doi: 10.1364/0E.23.008974. PubMed PMID: 25968734.

49. Dijkstra EW. A note on two problems in connexion with graphs. Numer Math. 1959;1(1):269-71. doi: 10.1007/BF01386390.

50. Kajić V, Esmaeelpour M, Považay B, Marshall D, Rosin PL, Drexler W. Automated choroidal segmentation of $1060 \mathrm{~nm}$ OCT in healthy and pathologic eyes using a statistical model. Biomed Opt Express. 2012;3(1):86-103. doi: 10.1364/ BOE.3.000086. PubMed PMID: 22254171. PubMed PMCID: PMC3255345.

51. Torzicky T, Pircher M, Zotter S, Bonesi M, Götzinger E, Hitzenberger CK. Automated measurement of choroidal thickness in the human eye by polarization sensitive optical coherence tomography. Opt Express. 2012;20(7):7564-74. doi: 10.1364/ OE.20.007564. PubMed PMID: 22453435. PubMed PMCID: PMC4392798.

52. Tian J, Marziliano P, Baskaran M, Tun TA, Aung T. Automatic segmentation of the choroid in enhanced depth imaging optical coherence tomography images. Biomedical optics express. 2013;4(3):397411. doi: 10.1364/BOE.4.000397. PubMed PMID: 23504041. PubMed PMCID: PMC3595084.

53. Garvin MK, Abràmoff MD, Kardon R, Russell SR, Wu X, Sonka M. Intraretinal layer segmentation of macular optical coherence tomography images using optimal 3-D graph search. IEEE Trans Med Imag. 2008;27(10):1495-505. doi: 10.1109/ TMI.2008.923966. PubMed PMID: 18815101. PubMed PMCID: PMC2614384.

54. Zhang L, Lee K, Niemeijer M, Mullins RF, Sonka $M$, Abràmoff MD. Automated segmentation of the choroid from clinical SD-OCT. Invest Ophthalmol Vis Sci. 2012;53(12):7510-9. doi: 10.1167/ iovs.12-10311. PubMed PMID: 23060139. PubMed PMCID: PMC3490539.

55. Hu Z, Wu X, Ouyang Y, Ouyang Y, Sadda SR. Semiautomated segmentation of the choroid in spectral-domain optical coherence tomography volume scans. Invest Ophthalmol Vis Sci. 2013;54(3):1722-9. doi: 10.1167/iovs.12-10578. PubMed PMID: 23349432.

56. Lee S, Fallah N, Forooghian F, Ko A, Pakzad-Vaezi $\mathrm{K}$, et al. Comparative analysis of repeatability of manual and automated choroidal thickness measurements in nonneovascular age-related macular degeneration. Invest Ophthalmol Vis Sci. 
2013;54(4):2864-71. doi: 10.1167/iovs.12-11521. PubaMed PMID: 23538060.

57. Gerendas BS, Waldstein SM, Simader C, et al. Three-dimensional automated choroidal volume assessment on standard spectral-domain optical coherence tomography and correlation with the level of diabetic macular edema. Am J Ophthalmol. 2014;158(5):1039-48. doi: 10.1016/j. ajo.2014.08.001. PubMed PMID: 25127697. PubMed PMCID: PMC5750044.

58. Srinath N, Patil A, Kumar VK, Jana S, Chhablani $\mathrm{J}$, Richhariya A. Automated detection of choroid boundary and vessels in optical coherence tomography images. 36th Annual International Conference of the IEEE Engineering in Medicine and Biology Society. Chicago, USA: IEEE; 2014. p. 166-9. doi: 10.1109/embc.2014.6943555.

59. Vupparaboina KK, Nizampatnam S, Chhablani J, Richhariya A, Jana S. Automated estimation of choroidal thickness distribution and volume based on OCT images of posterior visual section. Comput Med Imag Graph. 2015;46:315-27. doi: 10.1016/j.compmedimag.2015.09.008. PubMed PMID: 26526231

60. Shi F, Tian B, Zhu W, Xiang D, Zhou L, Xu H, Chen $X$. Automated choroid segmentation in three-dimensional 1-jm wide-view OCT images with gradient and regional costs. J Biomed Opt. 2016;21(12):126017. doi: 10.1117/1. JB0.21.12.126017. PubMed PMID: 28006046.

61. Twa MD, Schulle KL, Chiu SJ, Farsiu S, Berntsen DA. Validation of Macular Choroidal Thickness Measurements from Automated SD-OCT Image Segmentation. Optom Vis Sci. 2016;93(11):138798. doi: 10.1097/0PX.0000000000000985. PubMed PMID: 27668634. PubMed PMCID: PMC5108587.

62. Chen Q, Niu S, Fang W, Shuai Y, Fan W, Yuan $S$, Liu Q. Automated choroid segmentation of three-dimensional SD-OCT images by incorporating EDI-OCT images. Comput Methods Programs Biomed. 2018;158:161-71. doi: 10.1016/j. cmpb.2017.11.002. PubMed PMID: 29544782.

63. Mazzaferri J, Beaton L, Hounye G, Sayah DN, Costantino S. Open-source algorithm for automatic choroid segmentation of OCT volume reconstructions. Sci Rep. 2017;7:42112. doi: 10.1038/ srep42112. PubMed PMID: 28181546. PubMed
PMCID: PMC5299605.

64. Al-Bander B, Williams BM, Al-Taee MA, Al-Nuaimy W, Zheng $Y$. A novel choroid segmentation method for retinal diagnosis using deep learning. 10th International Conference on Developments in eSystems Engineering (DeSE); Paris, France: IEEE; 2017. p. 182-7. doi: 10.1109/DeSE.2017.37.

65. Chen M, Wang J, Oguz I, VanderBeek BL, Gee JC. Automated segmentation of the choroid in edioct images with retinal pathology using convolution neural networks. Fetal, Infant and Ophthalmic Medical Image Analysis. 2017:177-84. doi: 10.1007/978-3-319-67561-9_20. PubMed PMID: 29757338. PubMed PMCID: PMC5947958.

66. Wang C, Wang YX, Li Y. Automatic choroidal layer segmentation using markov random field and level set method. IEEE J Biomed Health Inform. 2017;21(6):1694-702. doi: 10.1109/ JBHI.2017.2675382.

67. Salafian B, Kafieh R, Rashno A, Pourazizi M, Sadri S. Automatic segmentation of choroid layer in edi oct images using graph theory in neutrosophic space. ArXiv. 2018.

68. Masood S, Fang R, Li P, Li H, Sheng B, Mathavan $A$, et al. Automatic Choroid Layer Segmentation from Optical Coherence Tomography Images Using Deep Learning. Sci Rep. 2019;9(1):3058. doi: 10.1038/s41598-019-39795-x. PubMed PMID: 30816296. PubMed PMCID: PMC6395677.

69. George N, Jiji CV. Two stage contour evolution for automatic segmentation of choroid and cornea in OCT images. Biocybern Biomed Eng. 2019;39(3):686-96. doi: 10.1016/j. bbe.2019.05.012.

70. Dice LR. Measures of the amount of ecologic association between species. Ecology. 1945;26(3):297302. doi: 10.2307/1932409.

71. Boddy R, Smith GL. Statistical methods in practice: for scientists and technologists. Chichester, UK: John Wiley \& Sons; 2009.

72. Lehmann EL, Casella G. Theory of point estimation. Springer Science \& Business Media; 2006.

73. Willmott CJ, Matsuura K. Advantages of the mean absolute error (MAE) over the root mean square error (RMSE) in assessing average model performance. Clim Res. 2005;30(1):79-82. doi: 10.3354/ cr030079. 